dig for food. Thus the woodpecking habit would seem to be older than the woodpecker; and that the pairtoed foot is not specially adapted for climbing is also shown in the fact that in several genera of woodpeckers the hallux or true hind-toe is absent or aborted, so that the foot ceases to be pair-toed.

\section{Detecting Insect Pest Attacks}

Mr. A. M. Massee, of the East Malling Research Station, is to be congratulated on his simple methods for early detection of epidemics of certain insect pests of fruit trees (Ann. Rep. East Malling Research Sta., 1931, pp. 78-80). For example, attacks of caterpillar, aphis, or sucker can be detected if twigs from trees in various parts of the orchard are caused to produce growth early by placing them in water in a warm place. The growing spurs reveal the presence of pests which would not be recognisable in the ordinary way until the natural time of bud break. It is also possible to spray black currant bushes against big bud mite at the most effective moment, namely, just when the mites are migrating. A few affected branches are placed in a jar containing sand and water in the open; daily observation with a hand lens will show when the mites appear on the outsides of the buds, and so will also indicate when spraying should be performed. The idea will help materially to raise horticulture to the status of a more exact science.

\section{Modern Milk Production}

Success in dairy farming depends on the exercise of efficiency with economy in all departments of the industry. The main factors concerned in the cost of production are the milk-producing quality of the race and herd, the care given to breeding for milk production, housing, feeding, and general management. For the guidance of dairy herdsmen, the Ministry of Agriculture has issued a pamphlet (Bulletin No. 52, price $9 d$. net) in which all these factors are considered, and in which the most up-to-date methods of milk production are set forth clearly and in well-classified arrangement. The Ministry has had the advantage of the assistance of experts who have carried out extensive investigations into the many questions connected with the business of milk production, and it goes almost without saying that the result is an attractive as well as a highly practical guide.

\section{A Serious Poultry Disease}

The Ministry of Agriculture and Fisheries issues a warning against the possibility of introducing the disease known as bacillary white diarrhca into flocks by the purchase of infected chicks from hatcheries. Serious losses may be caused by such agency, the more to be regretted as a little preliminary precaution might have avoided the introduction of the disease altogether. It is conveyed to the chicks by infected hens through their eggs, so that it is of the utmost importance that the breeding stock should be free from the disease. Now, hens which are carriers of the disease may be recognised as such by the agglutina. tion test, and eliminated from the breeding stock; so that a purchaser of eggs for hatching or day-old chicks should insist that the stock from which his supplies are obtained has been declared free of reacting birds. A number of county authorities for agricultural education now accredit poultry-breeding farms where the quality of the breeding stock reaches an approved standard, and where birds have been sub. jected to the agglutination test according to regulations laid down by the scheme.

\section{Lecture Tours at the Natural History Museum}

OwING to the success achieved by the appointment of guide-lecturers at the national museums and galleries, it has been decided to inaugurate more advanced lecture tours at the British Museum (Natural History), to be conducted by members of the scientific staff of the Museum, on Mondays at 12 noon, commencing on Oct. 3. It is announced that Miss M. R. J. Edwards has been appointed official guide-lecturer at the Museum in succession to the late Mr. J. H. Leonard, who died at the end of last year (see Nature of Jan. 2, p. 15).

\section{Announcements}

Mr. W. F. Hugains, principal assistant of the physics department of the National Physical Laboratory, has been appointed secretary of the Laboratory in succession to Mr. F. J. Selby, who recently retired.

Miss Penelope Jenkin, of Newnham College, Cambridge, has been appointed by the trustees as Ray Lankester investigator at the Marine Biological Laboratory, Plymouth, for the year 1933. Miss Jenkin will attempt to correlate the rate of photosynthesis of diatom cultures immersed at different depths in the sea, off Plymouth, with photoelectric measurements of light penetration made by Dr. W. R. G. Atkins.

A Demonstration of contraceptive technique will be given at the Clinic of the Society for Constructive Birth Control on Oct. 5, at 2.30-5 P.M., to medical practitioners and senior medical students only, who will be given an opportunity of practising various methods under tuition on women patients. Lectures and demonstrations will be conducted by Dr. Beddow Bayly and Dr. Evelyn Fisher and the midwife-incharge. Applications for tickets (which are necessary) should be made to the Honorary Secretary of the Society, 108 Whitfield Street, W.1.

ApPlicatrons are invited for the following appointments, on or before the dates mentioned :-An engineer in the Burma Marine Service-The High Commissioner for India, General Department, India House, Aldwych, London, W.C.2 (Oct. 15). A Lawrence research student for research in some sub. ject related to the cause and cure of disease in man and animals-The Assistant Secretary of the Royal Society, Burlington House, London, W.1 (Oct. 24). A professor of chemical technology at the University of Bombay-The Secretary, Universities Bureau of the British Empire, 88A Gower Street, London, W.C.I (Nov. 7). An assistant to teach general mechanical engineering at the Darlington Technical College-Chief Education Officer, Education Office, Darlington.

$$
\text { No. 3283, Vor. 130] }
$$

